\title{
Article \\ Thermal Gelation for Synthesis of Surface-Modified Silica Aerogel Powders
}

\author{
Kyoung-Jin Lee, Jae Min Lee, Ki Sun Nam and Haejin Hwang *(D) \\ Department of Materials Science and Engineering, Inha University, Incheon 22212, Korea; \\ legna211@naver.com (K.J.L.); 22201275@inha.edu (J.M.L.); skarltjs2@naver.com (K.S.N.) \\ * Correspondence: hjhwang@inha.ac.kr; Tel.: +82-32-860-7521
}

\begin{abstract}
A spherical silica aerogel powder with hydrophobic surfaces displaying a water contact angle of $147^{\circ}$ was synthesized from a water glass-in-hexane emulsion through ambient pressure drying. Water glass droplets containing acetic acid and ethyl alcohol were stabilized in $n$-hexane with a surfactant. Gelation was performed by heating the droplets, followed by solvent exchange and surface modification using a hexamethyldisilazane (HMDS) $/ n$-hexane solution. The $\mathrm{pH}$ of the silicic acid solution was crucial in obtaining a highly porous silica aerogel powder with a spherical morphology. The thermal conductivity, tapped density, pore volume, and BET surface area of the silica aerogel powder were $22.4 \mathrm{~mW} \cdot \mathrm{m}^{-1} \mathrm{~K}^{-1}, 0.07 \mathrm{~g} \cdot \mathrm{cm}^{-3}, 4.64 \mathrm{~cm}^{3} \cdot \mathrm{g}^{-1}$, and $989 \mathrm{~m}^{2} \cdot \mathrm{g}^{-1}$, respectively. Fourier transform infrared (FT-IR) spectroscopy analysis showed that the silica granule surface was modified by $\mathrm{Si}-\mathrm{CH}_{3}$ groups, producing a hydrophobic aerogel.
\end{abstract}

Keywords: silica aerogel; thermal gelation; porous; thermal conductivity; hydrophobicity

check for

updates

Citation: Lee, K.-J.; Lee, J.M.; Nam, K.S.; Hwang, H. Thermal Gelation for Synthesis of Surface-Modified Silica Aerogel Powders. Gels 2021, 7, 242. https://doi.org/10.3390/gels7040242

Academic Editors: István Lázár and Melita Menelaou

Received: 31 October 2021

Accepted: 25 November 2021

Published: 29 November 2021

Publisher's Note: MDPI stays neutral with regard to jurisdictional claims in published maps and institutional affiliations.

Copyright: (c) 2021 by the authors. Licensee MDPI, Basel, Switzerland. This article is an open access article distributed under the terms and conditions of the Creative Commons Attribution (CC BY) license (https:/ / creativecommons.org/licenses/by/ $4.0 /)$.

\section{Introduction}

A silica aerogel is a mesoporous solid with outstanding properties, including low thermal conductivity, a low dielectric constant, a low refractive index, and high specific surface area. Silica aerogels are considered as promising materials for thermal insulation [1,2], anti-reflection coatings [3], low dielectrics [4], supports for cosmetics [5], adsorbents [6-8], and viscosity agents [9].

Silica aerogels can be fabricated in the form of a monolith or a powder. Silica aerogel monoliths are normally produced by supercritical or ambient pressure drying of a wet gel derived via hydrolysis, and polymerization of alkoxide- or water glass-based precursor solutions [10]. Wei et al. reported an ambient pressure-dried silica aerogel monolith with multiple surface modifications, low thermal conductivity $(36 \mathrm{~mW} / \mathrm{mK})$, and high porosity $(97 \%)$ [11]. However, the repeated modification process to transfer hydrophilicity to the hydrophobic surface of the silica aerogel monolith is tedious and requires an extremely long processing time. The reactions between the surface modification agent and silanol groups $(\mathrm{Si} \mathrm{OH})$ are diffusion-limited processes, suggesting that the processing time for surface modification increases in proportion to the size of the silica aerogel sample. In addition, silica aerogel monoliths are fragile [12].

Silica aerogel powders and granules are easily and inexpensively fabricated and have a short processing time compared with silica aerogel monoliths. Researchers have recently reported novel methods for rapid synthesis of hydrophobic silica aerogel powders and granules using ambient pressure drying. Bhagat et al. proposed a one-step process with simultaneous surface modification, solvent exchange, and sodium ion removal [13]. Huber et al. presented a one-pot synthesis method for silica aerogel granulates [14]. They argued that gelation after surface modification is crucial for reducing the amount of solvent and production time. In our previous study focusing on catalysts for hydrolysis and condensation of water glass, we proposed a novel fast synthesis technique for spherical silica aerogel powders with a narrow particle size distribution. This synthesis technique reduced 
the total processing time to less than $2 \mathrm{~h} \mathrm{[15].} \mathrm{However,} \mathrm{silica} \mathrm{aerogel} \mathrm{powders} \mathrm{using} \mathrm{the}$ aforementioned fast synthesis processes exhibit some drawbacks. The powder quality is somewhat poor. Tapped density and pore volume are lower than for supercritically dried aerogels $[10,11,16]$. In addition, the silica aerogels lack particle size homogeneity.

Silica aerogel powders can be prepared by crushing bulk dried silica aerogel or using emulsion polymerization techniques. Although it appears simple and straightforward, crushing silica aerogel bulk is cumbersome, and the resulting powder is bulky. In addition, size and shape control is challenging. Emulsion polymerization is a promising technique for controlling the size and shape of silica aerogel particles. Spherical silica aerogel powder is produced from a water glass-in-hexane emulsion. The particle size of the silica aerogel can be determined by the water glass droplet size, which depends on the force applied to the homogenizer and the emulsifier content.

The silica aerogel powder produced by emulsion polymerization in our previous study had a tapped density of $0.12 \mathrm{~g} \cdot \mathrm{cm}^{-3}$, a pore volume of $2.35 \mathrm{~cm}^{3} \cdot \mathrm{g}^{-1}$, and a thermal conductivity of $26 \mathrm{~mW} \cdot \mathrm{m}^{-1} \mathrm{~K}^{-1}$, somewhat inferior to commercially available silica aerogel powders. We believe that the inferior properties are attributed to inhomogeneous hydrolysis and gelation in the water glass-in-hexane emulsion. In this study, a novel synthesis technique is proposed to produce high-quality spherical silica aerogel particles. We used a novel gelation process (thermal gelation), used for a sol-gel transition of natural polymers such as methylcellulose $[17,18]$. Water glass droplets containing acid and a gelation catalyst were stabilized in $n$-hexane with a surfactant, followed by thermal gelation, surface modification, and solvent exchange.

\section{Materials and Methods}

A water glass sodium silicate solution (silica content: $28-30 \mathrm{wt} . \%, \mathrm{SiO}_{2}: \mathrm{Na}_{2} \mathrm{O}=3.4: 1$, Young Il Chemical Co., Ltd., Incheon, Korea) was used as the starting material. Initially, the water glass solution was diluted to $5.3-8.7 \mathrm{wt} . \%$ with deionized water; $75 \mathrm{~mL}$ of water glass, $5 \mathrm{~mL}$ of acetic acid (99.5\%, Samchun Pure Chemical, Pyeongtaek, Korea), and $5 \mathrm{~mL}$ of ethyl alcohol (95.0\%, Samchun Pure Chemical) were mixed simultaneously. Ethyl alcohol was used as a condensation (gelation) catalyst, and as a con-solvent because a protic solvent such as ethyl alcohol can promote condensation. Next, $85 \mathrm{~mL}$ of $n$-hexane (95\%, Samchun Pure Chemical) containing a surfactant, sorbitan monooleate (Span80, Junsei Chemical Co., Ltd., Tokyo, Japan), was added to the water glass/acetic acid/ethyl alcohol solution. The water glass solution to $n$-hexane ratio was fixed at 1 . Water glass and $n$-hexane were emulsified using a homogenizer (UltraTurrax IKA T25:S25D-10G-KS, IKA Werke, Konigswinter, Germany) at $6000 \mathrm{rpm}$ for $10 \mathrm{~min}$. A stable water glass-in-hexane emulsion was obtained and heated at $60^{\circ} \mathrm{C}$ for condensation (thermal gelation).

Most of the $n$-hexane was drained from the emulsion, and the silica wet gel spheres were immersed in $150 \mathrm{~mL}$ of ethyl alcohol. Silica wet gel spheres were solvent-exchanged with ethyl alcohol, which can induce hydrogel-to-alcogel transformation. The surfaces of the silica alcogel spheres were chemically modified in $150 \mathrm{~mL}$ of $20 \%$ hexamethyldisilazane (HMDS, $98 \%$, Samchun Pure Chemical) $/ n$-hexane solution at $60^{\circ} \mathrm{C}$ for $3 \mathrm{~h}$. The silylated silica wet gel spheres were washed using an ethyl alcohol $/ n$-hexane solution to remove the remaining surface modification agents and reaction products. The surface modification process was repeated three times. The silica wet gel spheres were dried at $100^{\circ} \mathrm{C}$ in ambient pressure for $1 \mathrm{~h}$. A schematic of the spherical silica aerogel powder preparation procedure is shown in Figure 1. 


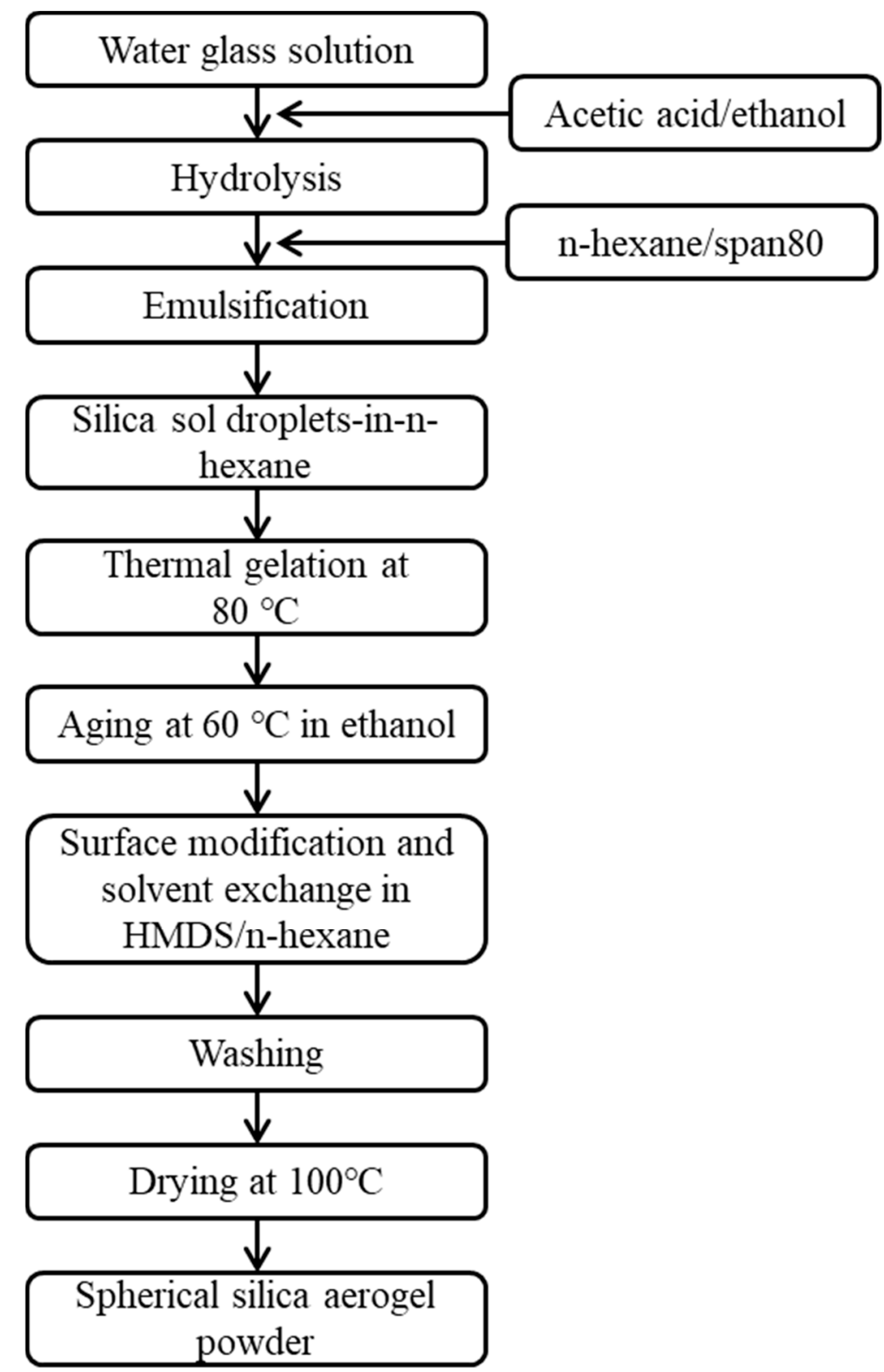

Figure 1. Experimental flow chart for synthesis of spherical silica aerogel powder.

The tapped density of the aerogel powders was determined using a tapping density tester (TAP-2S, Logan Instruments Co., Somerset, NJ, USA). The viscosity of the silicic acid solution was measured using a viscometer (LVT B, Brookfield, Chander, AZ) at $25^{\circ} \mathrm{C}$. The surface area was determined by BET analysis from the amount of $\mathrm{N}_{2}$ gas adsorbed at different partial pressures $(0.01<\mathrm{p} / \mathrm{p} 0<1$, ASAP 2010; Micrometrics, Norcross, GA, USA). Fourier transform infrared (FT-IR) spectroscopy (FTS-165, Bio-Rad, Hercules, CA, USA) was used to confirm the surface chemical structure of the aerogels in the wavenumber range of $400-4000 \mathrm{~cm}^{-1}$. The contact angle of the water droplet on the silica aerogel powder was calculated from the height and width of the water droplet [19].

The thermal conductivity of the silica aerogel powder was measured using the heat flow metering method with a heat flow meter (HFM 436 Lambda, NETZSCH, Selb, Germany). A silica aerogel powder was placed between two flat plates $(25 \mathrm{~cm} \times 25 \mathrm{~cm})$, with the upper and lower plates set at $35^{\circ} \mathrm{C}$ and $15^{\circ} \mathrm{C}$, respectively. When thermal equilibrium was reached, the thermal conductivity was estimated using Fourier's law. The thermal conductivity was calculated from the heat flux, the thickness of the silica aerogel powder, 
and the temperature gradient of the two plates. The microstructure of the silica aerogel powder was observed using field-emission scanning electron microscopy (FESEM, S-4200, Hitachi, Tokyo, Japan).

\section{Results and Discussion}

Both homogeneous gelation and surface modification are required to obtain highquality hydrophobic silica aerogel powders (with low bulk density and high pore volume) [20]. Generally, hydrophobic silica aerogels are synthesized through gelation of silica sol or silicic acid solution and subsequent solvent exchange (SE) and surface modification (SM) using hydrophobizing agents. The SE and SM processes require a long processing time. To reduce the processing time, a one-pot process with simultaneous gelation, $\mathrm{SE}$, and SM via the co-precursor method has been proposed [13, 14]. However, the one-pot process results in some reduced physical properties, including density and pore volume [21].

In this study, acetic acid and ethyl alcohol catalysts were used for the hydrolysis and condensation of the water glass solution. Generally, silica sol made with weak acids such as acetic acid is less stable than sol made with strong acids such as hydrochloric and nitric acids. In our previous study, it was deduced that acetic acid and isopropanol catalysts for hydrolysis and condensation of water glass were crucial for spherical silica aerogel powder synthesis with a narrow particle size distribution and a shorter production time. The $\mathrm{pH}$ of the silica sol made with acetic acid was 4.5-5.0; the silica sol exhibited adequate gelation time, neither long nor short, suggesting that silica sol catalyzed with acetic acid is stable.

When acetic acid and ethyl alcohol catalysts were added to the water glass solution, gelation did not occur in this step because the concentration of water glass was low (5-8\%) and the silica sol made with acetic acid and ethyl alcohol was sufficiently stable at $\mathrm{pH}=4.5-5.0$. Gelation occurred when the silica sol in the $n$-hexane emulsion was heated to $60^{\circ} \mathrm{C}$. A silica wet gel with a spherical morphology was obtained.

Figure $2 \mathrm{a}$, $\mathrm{b}$ show the tapped density of the obtained silica aerogel powders as a function of the water glass concentration and $\mathrm{pH}$ of the silicic acid solution. The lowest tapped density $\left(0.067 \mathrm{~g} \cdot \mathrm{cm}^{-3}\right)$ was obtained in a $6.6 \%$ water glass solution. Less than $6.6 \%$ water glass solution resulted in an increased tapped density. Above $6.6 \%$, the increase in the tapped density was somewhat reasonable because the tapped density of the aerogel is proportional to the concentration of the starting water glass solution. In Figure 2a, below $6.6 \%$, the tapped density increases again as a function of the water glass concentration. It can be inferred that this is associated with the $\mathrm{pH}$ of the silicic acid solution. The $\mathrm{pH}$ of the starting water glass solution was estimated to be 11.4 and does not depend on its concentration. In the silicic acid solution, a minimum tapped density was observed at $\mathrm{pH}=4.5$ (6.6\% water glass solution).
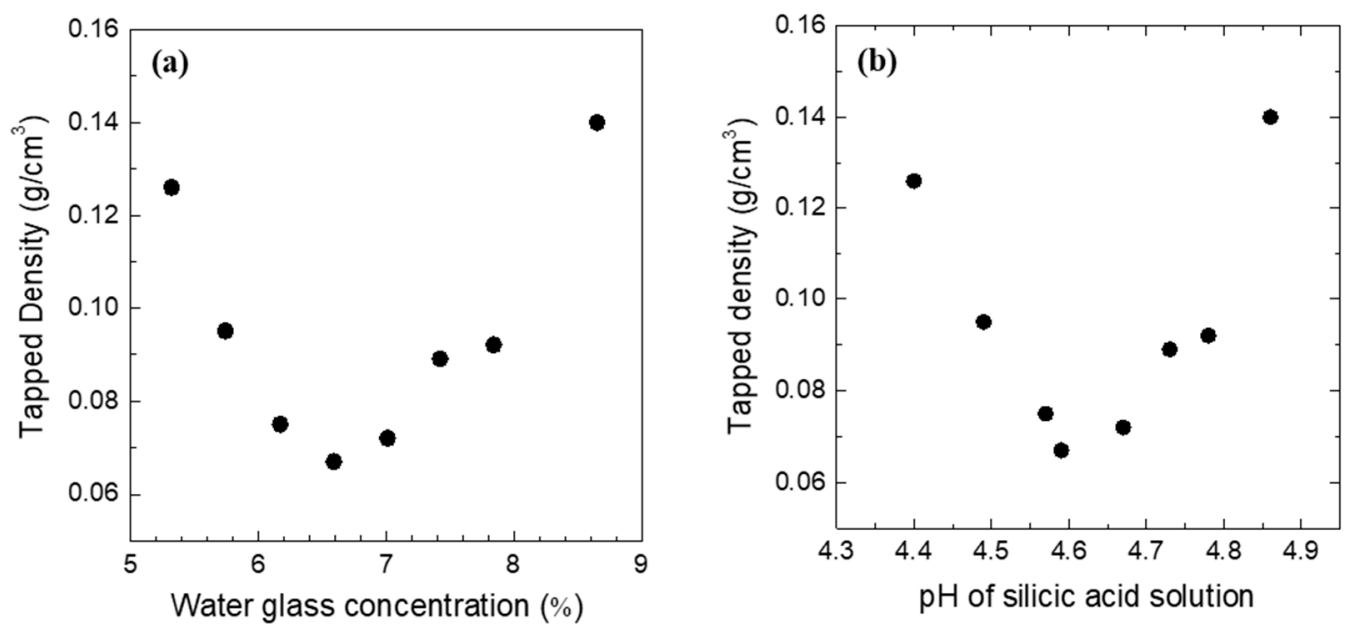

Figure 2. Tapped density of spherical silica aerogel powder as a function of water glass concentration (a) and $\mathrm{pH}$ of silicic acid solution (b). 
Sarawade et al. addressed the mechanism of sol-gel polymerization from a water glass solution with an acetic acid catalyst. The gelation time decreased as the $\mathrm{pH}$ of the silicic acid solution increased; they showed that the minimum gelation time ( $5 \mathrm{~min})$ was observed with a $\mathrm{pH}$ of 5-6 [22]. To obtain low-density silica aerogels, they used a silicic acid solution with a $\mathrm{pH}$ of 4 . Above $\mathrm{pH}=4$, the gelation is too fast, leading to an extremely unstable silica sol. Below $\mathrm{pH}=4$, the hydrolysis and condensation reactions are not sufficient in the gelation process, which can affect the properties of the final silica aerogel products [23].

Figure 3 shows the change in viscosity as a function of aging time for silicic acid solutions at different $\mathrm{pH}$ values. The viscosity abruptly increased to $400 \mathrm{cP}$ from $30-180 \mathrm{~min}$ at $\mathrm{pH}=5.08$ and 4.10 , respectively. The rate of viscosity change increased as the $\mathrm{pH}$ increased (acetic acid content decreased). Table 1 summarizes the gelation times of the silicic acid solutions and the tapped densities of the synthesized silica aerogel powders as a function of acetic acid content and $\mathrm{pH}$. The concentration of the water glass solution was $6.6 \%$. Gelation time is defined as the time after which the viscosity deviates from linearity [24]. The gelation time strongly depends on the $\mathrm{pH}$ of the silicic acid solution. As the acetic acid content increases, the $\mathrm{pH}$ value of the silicic acid solution decreases, and the gelation time gradually increases. The condensation rate is generally faster than the hydrolysis rate and increases with increasing $\mathrm{pH}$ from 4-10 [25].

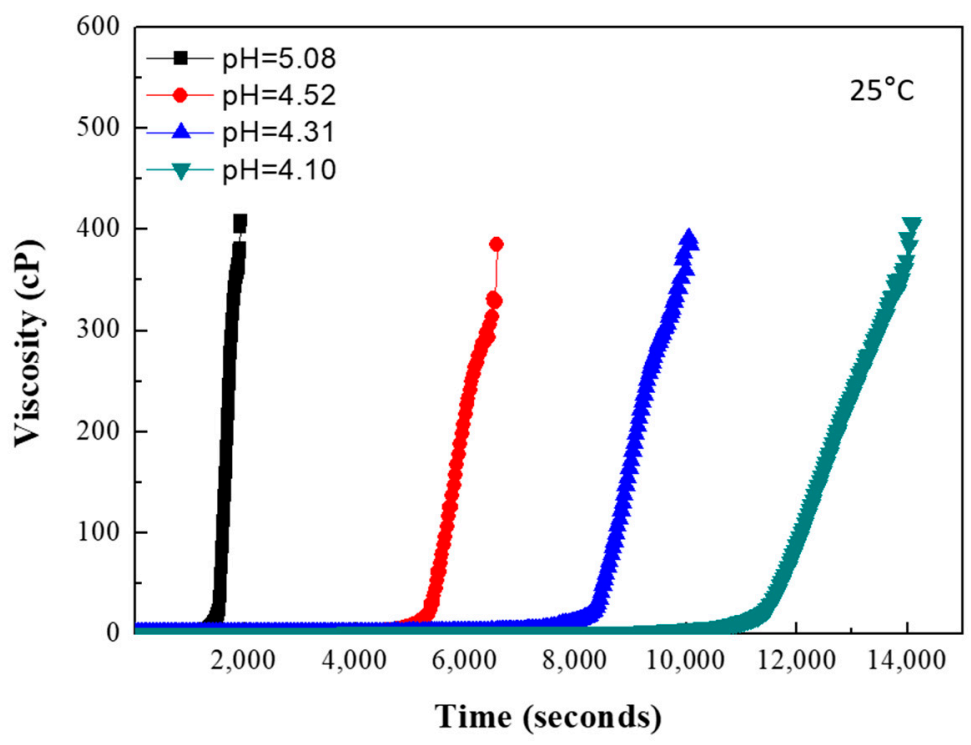

Figure 3. Viscosity of silicic acid solutions at different $\mathrm{pH}$ as a function of aging time.

Table 1. Gelation time of silicic acid solutions with different $\mathrm{pH}$ and tapped densities of silica aerogel powders (concentration of water glass solution: $6.6 \%$ ).

\begin{tabular}{cccc}
\hline $\begin{array}{c}\text { Acetic Acid Content } \\
(\mathbf{m L})\end{array}$ & $\begin{array}{c}\text { pH of Silicic Acid } \\
\text { Solution }\end{array}$ & $\begin{array}{c}\text { Gelation Time } \\
(\mathbf{m i n})\end{array}$ & $\begin{array}{c}\text { Tapped Density } \\
\left(\mathbf{g} \cdot \mathbf{c m}^{-3}\right)\end{array}$ \\
\hline 3 & 5.08 & 24 & 0.227 \\
5 & 4.52 & 85 & 0.090 \\
7 & 4.31 & 128 & 0.097 \\
10 & 4.10 & 180 & 0.236 \\
\hline
\end{tabular}

From Table 1, the silica aerogel powder sample prepared with a water glass concentration of $6.6 \%$ and a pH value of 4.52 exhibited the lowest tapped density $\left(0.090 \mathrm{~g} \cdot \mathrm{cm}^{-3}\right)$, which was also observed in the aerogel powder sample with a water glass concentration higher than $6.6 \%$. This result suggests that an optimum $\mathrm{pH}$ exists at which the aerogel powder sample exhibits the lowest tapped density. When the $\mathrm{pH}$ of the silicic acid solution is higher than approximately 4.5 , gelation is too fast, which can lead to an increased tapped 
density owing to insufficient time for solvent exchange and surface modification. In Table 1 , the tapped density of the silica aerogel powder sample prepared using a silicic acid solution with a $\mathrm{pH}$ of 5.08 was significantly higher than those of silica aerogel powder samples with $\mathrm{pH}$ values of 4.31 and 4.51 . The tapped density increased at $\mathrm{pH}=4.1$ (acetic acid content: $10 \mathrm{~mL}$ ) owing to the slow hydrolysis and condensation rate at a low $\mathrm{pH}$. If the $\mathrm{pH}$ of the silicic acid solution is too low, hydrolysis, condensation, and surface modification reactions occur simultaneously, which can have a detrimental effect on the mesoporous structure development of silica aerogel.

Figure 4a-f show SEM images of silica aerogel powders prepared with different water glass concentrations. Figure $4 a-c$ show that the obtained silica aerogel powders have a spherical shape, with average estimated sizes of approximately $10-30 \mu \mathrm{m}$, regardless of the water glass concentration (Figure S1). This result suggests that the water glass concentration does not significantly affect the size and morphology (sphericity) of the silica aerogel powders. High-magnification SEM images (Figure $4 \mathrm{~d}-\mathrm{f}$ ) show that the silica particles possess a typical highly porous three-dimensional network structure consisting of silica nanoparticles, although their tapped densities are slightly different.
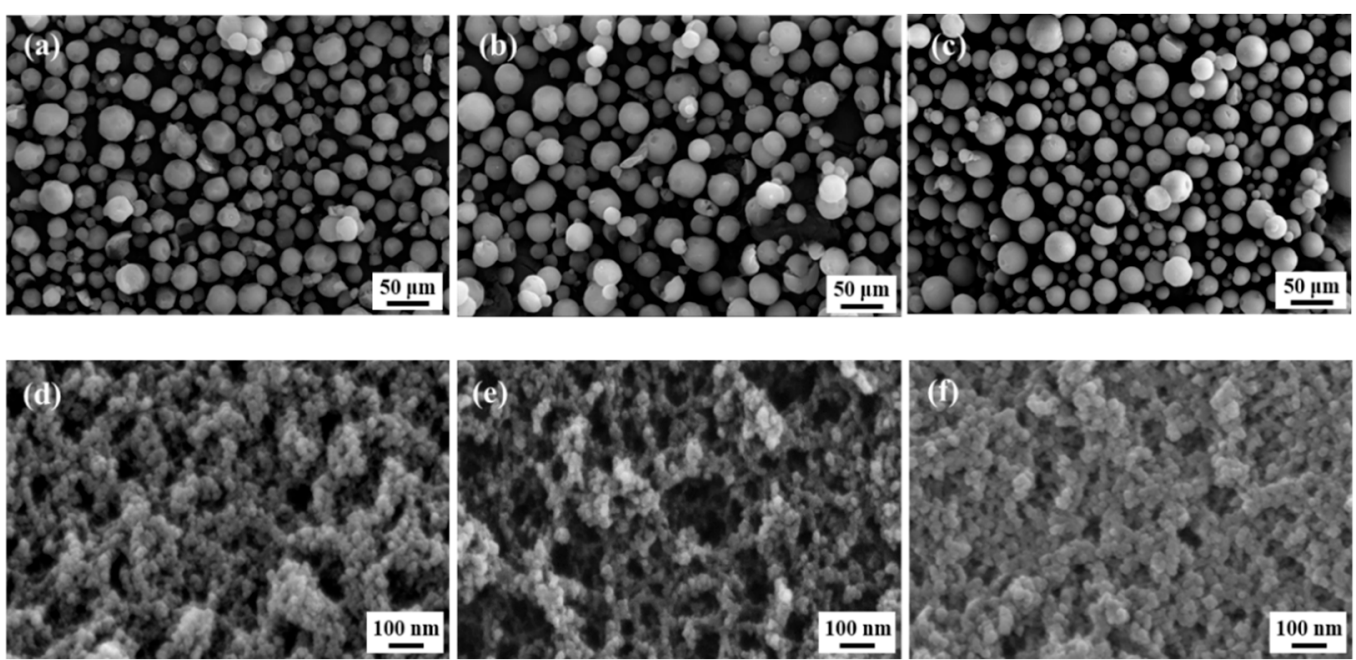

Figure 4. SEM images of silica aerogel powders prepared from (a,d) $5.7 \%$; (b,e) $6.6 \%$; (c,f) $8.7 \%$ water glass solutions.

$\mathrm{N}_{2}$ adsorption-desorption isotherms of the silica aerogel powder are shown in Figure 5. $\mathrm{N}_{2}$ absorption sharply increases near the high relative pressure area (Type IV adsorptiondesorption isotherm with type $\mathrm{H} 1$ hysteresis loop), indicating that the silica aerogel is mesoporous [26,27]. It is known that hysteresis is attributed to capillary condensation and evaporation occurring in the mesopores [28]. The hysteresis loop in Figure $5 \mathrm{~b}$ was found to be more significant, indicating many mesopores in the silica aerogel powder sample with a water glass concentration of $6.6 \%$. 

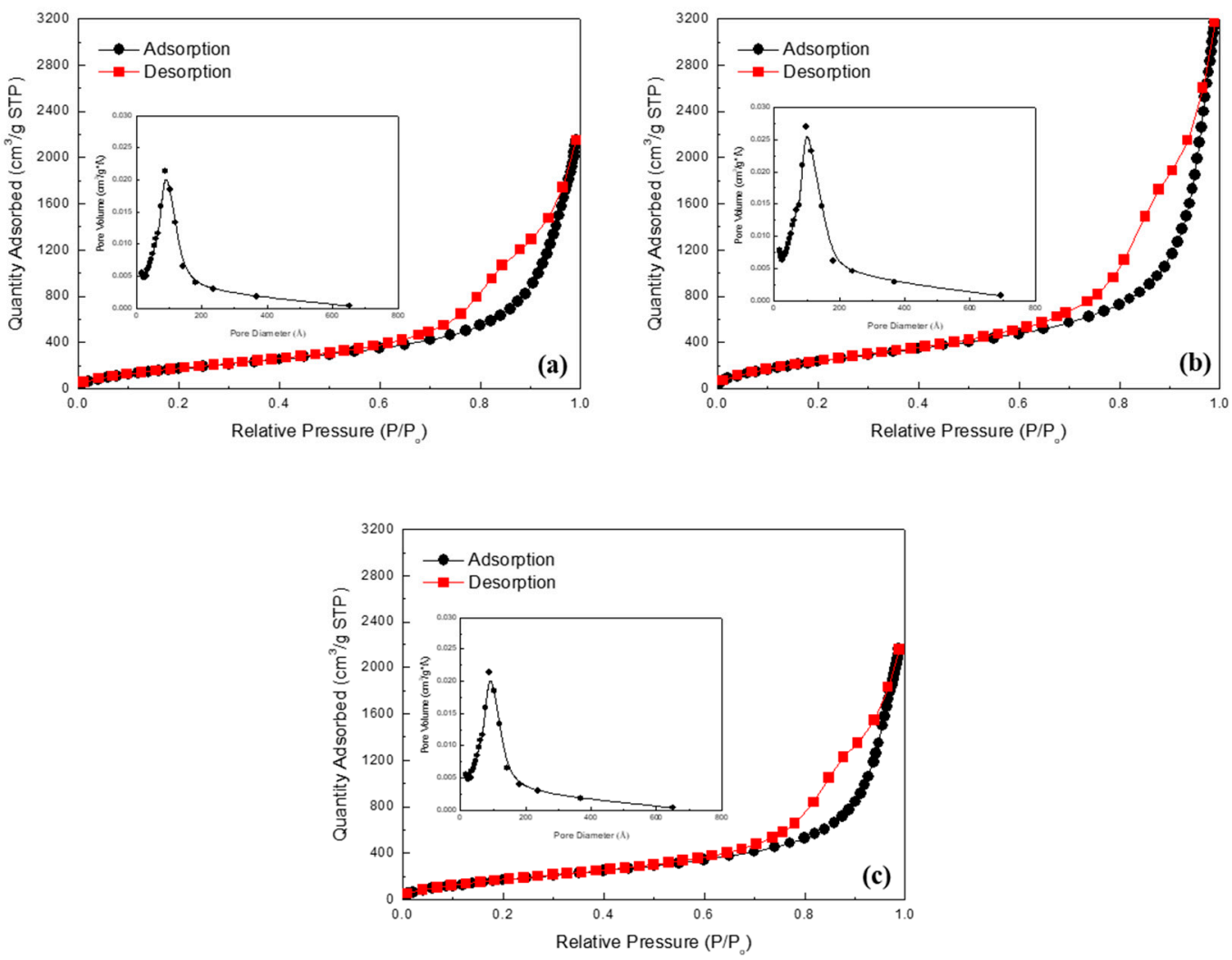

Figure 5. Adsorption-desorption isotherms of spherical silica aerogel powders synthesized from (a) $5.3 \%$; (b) $6.6 \%$; (c) $7.0 \%$ water glass solutions. Insets show pore size distribution based on $\mathrm{BJH}$ (adsorption).

Table 2 summarizes the physical properties of silica aerogel powders prepared with different water glass concentrations. Tapped density, BET specific surface area, and pore volume strongly depend on the water glass concentration. However, the water glass concentration does not affect the size of the mesopores. The mean pore diameter ranges from 17-19 $\mathrm{nm}$. However, in Figure 4, it appears that the macropore size and distribution changes with the water glass concentration. This observed phenomenon is associated with the difference in agglomeration behavior between secondary silica particles. Depending on the $\mathrm{pH}$ of silicic acid solution with different water glass concentrations, silica aerogels had different macrostructures. The agglomeration between silica particles increases with an increase in the $\mathrm{pH}$ of the silicic acid solution [29], leading to the formation of macropores, as can be seen in Figure $4 \mathrm{~b}$. In the case of $8.7 \%$ of water glass concentration, the silica aerogel possessed denser macrostructure than $5.7 \%$ and $6.6 \%$ aerogel samples, which is due to the large shrinkage during ambient pressure drying.

Table 2. Physical properties of silica aerogel powders synthesized from different water glass concentrations.

\begin{tabular}{cccc}
\hline $\begin{array}{c}\text { Water Glass } \\
\text { Concentration (\%) }\end{array}$ & $\begin{array}{c}\text { Specific Surface } \\
\text { Area }\left(\mathbf{m}^{\mathbf{2}} \cdot \mathbf{g}^{-\mathbf{1}}\right)\end{array}$ & $\begin{array}{c}\text { Pore Volume } \\
\left(\mathbf{c m}^{\mathbf{3}} \cdot \mathbf{g}^{-\mathbf{1}}\right)\end{array}$ & $\begin{array}{c}\text { Mean Pore Diameter } \\
(\mathbf{n m})\end{array}$ \\
\hline 5.3 & 719 & 3.11 & 17.3 \\
5.7 & 731 & 3.20 & 17.5 \\
6.2 & 680 & 3.20 & 18.8 \\
6.6 & 989 & 4.64 & 18.8 \\
7.0 & 709 & 3.14 & 17.7 \\
\hline
\end{tabular}

In Table 1, the silica aerogel powder prepared using a $6.6 \%$ water glass concentration exhibits the maximum BET specific surface area of $989 \mathrm{~m}^{2} \cdot \mathrm{g}^{-1}$, and a pore volume of 
$4.64 \mathrm{~cm}^{3} \cdot \mathrm{g}^{-1}$. The excellent properties of the $6.6 \%$ water glass solution sample are the result of a more porous microstructure and a slightly smaller particle size than the $5.7 \%$ and $8.7 \%$ samples. An adequate water glass concentration and $\mathrm{pH}$ are crucial for the silicic acid solution to obtain a silica aerogel powder with a low bulk density and a high pore volume.

Fourier transform infrared (FTIR) spectroscopy was used to confirm the hydrophobicity of the silica aerogel powder samples; the corresponding FTIR spectra are shown in Figure 6. According to previous studies [30,31], the absorption peaks near $1090 \mathrm{~cm}^{-1}$, $760 \mathrm{~cm}^{-1}$, and $460 \mathrm{~cm}^{-1}$ can be attributed to the asymmetric, symmetric and bending modes of Si-O-Si, respectively. These peaks are characteristic of typical silica aerogel network structures. The peaks at $1260 \mathrm{~cm}^{-1}$ and $850 \mathrm{~cm}^{-1}$ indicate the presence of a Si-C bond; the peaks at $2960 \mathrm{~cm}^{-1}$ and $1600 \mathrm{~cm}^{-1}$ correspond to $\mathrm{C}-\mathrm{H}$ stretching. Peaks corresponding to the stretching vibration of O-H $\left(3455 \mathrm{~cm}^{-1}\right.$ and $\left.1635 \mathrm{~cm}^{-1}\right)$ and Si-OH $\left(\sim 800 \mathrm{~cm}^{-1}\right)$ were not observed in any of the silica aerogel powder samples [32]. Thus, it can be inferred that the silica aerogel was modified into a hydrophobic form by the surface methyl groups $\left(-\mathrm{CH}_{3}\right)$. Photographs of water droplets on the silica aerogel powders prepared with water glass concentrations of 5.7\%, 6.6\%, and 8.7\% are shown in Figure 7. The contact angles of the silica aerogel powder from the $6.6 \%$ water glass solution exhibited the highest contact angle of $147^{\circ}$ (hydrophobicity); the contact angle decreased with increasing tapped density of the silica aerogel powder, suggesting that the contact angle (good hydrophobicity) is closely related to the tapped density of the silica aerogel powder. In general, the density of the silica aerogel depends on the degree of surface modification by functional groups. In other words, the high degree of modification results in low density because the pore water can be effectively exchanged by ethyl alcohol and $n$-hexane. Thus, it appears that the surface of the low-density silica aerogel is modified with large number of function groups, which can lead to good hydrophobicity.

The spherical silica aerogel powders prepared with water glass concentrations of $5.3 \%$ and $6.6 \%$ exhibited thermal conductivities of $24.2 \mathrm{mWm}{ }^{-1} \cdot \mathrm{K}^{-1}$ and $22.4 \mathrm{mWm}{ }^{-1} \cdot \mathrm{K}^{-1}$, respectively. Within our system, silica aerogel powder with a lower tapped density and higher pore volume exhibits a lower thermal conductivity. Although the thermal conductivity $\left(22.4 \mathrm{~mW} \cdot \mathrm{m}^{-1} \cdot \mathrm{K}^{-1}\right)$ obtained in this study is somewhat lower than that of previously reported silica aerogel powder $\left(\sim 14 \mathrm{~mW} \cdot \mathrm{m}^{-1} \cdot \mathrm{K}^{-1}\right)$ [14], it is comparable to that of commercially available silica aerogel powder with a similar particle size [33]. Thus, the silica aerogel powder obtained in this study can be used commercially in the field of superinsulation.

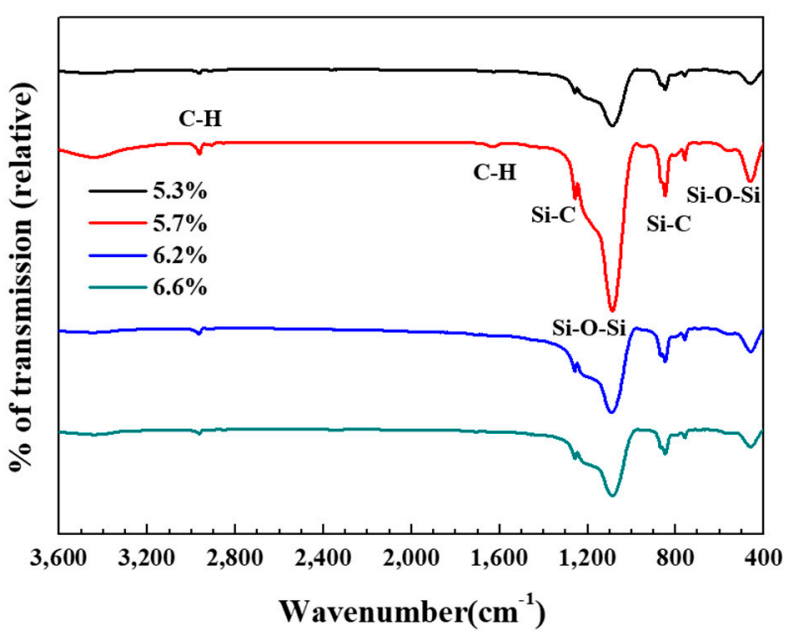

Figure 6. FT-IR spectra of silica aerogel powders prepared from water glass solutions with different concentrations. 


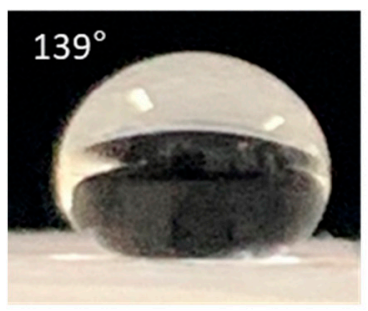

(a)

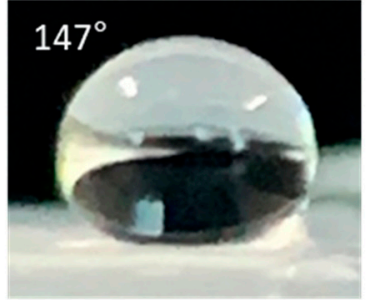

(b)

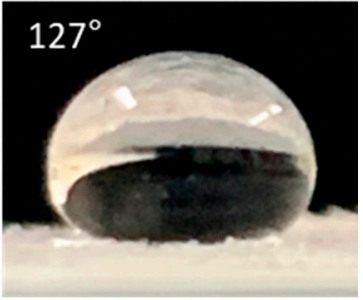

(c)

Figure 7. Photographs of water droplets on silica aerogel powders prepared with water glass solution concentrations of (a) $5.7 \%$; (b) $6.6 \%$; (c) $8.7 \%$.

\section{Conclusions}

Silica aerogel powders with spherical morphology and hydrophobic surfaces displaying a water contact angle of $147^{\circ}$ can be synthesized from water glass solutions via emulsion polymerization, thermal gelation, and ambient pressure drying. In this study, acetic acid and ethyl alcohol were used as hydrolysis and condensation catalysts, respectively. The ratio of acetic acid content to water glass concentration, affecting the $\mathrm{pH}$ value of the silicic acid solution, was crucial in obtaining a highly porous spherical silica aerogel powder. The silica aerogel powder obtained from a silicic acid solution with a $\mathrm{pH}$ of approximately 4.5 exhibited the lowest thermal conductivity, and the greatest specific surface area and pore volume. As the acetic acid content was increased (as the $\mathrm{pH}$ of the silicic acid solution decreased), the gelation time was significantly increased, which led to an increased tapped density. If the $\mathrm{pH}$ of the silicic acid solution was above 4.5 , the gelation rate was too fast and difficult to control, and physical properties of the silica aerogel powder such as pore volume and specific surface area deteriorated significantly.

Supplementary Materials: The following are available online at https:/ /www.mdpi.com/article/ 10.3390/gels7040242/s1, Figure S1: Particle size distribu-tions of silica aerogel powder samples prepared with different water glass concentrations.

Author Contributions: Conceptualization: H.H. and K.-J.L.; methodology: J.M.L. and K.S.N.; formal analysis: K.-J.L.; investigation: K.-J.L.; writing—original draft preparation: K.-J.L.; writing—review and editing: H.H.; supervision: H.H.; project administration: H.H. All authors have read and agreed to the published version of the manuscript.

Funding: This work was supported by a National Research Foundation of Korea (NRF) grant funded by the Korean government (MSIT) (No. 2020R1A5A1019131), and a National Research Foundation of Korea (NRF) grant (NRF-2020M3D1A2102918).

Data Availability Statement: Not applicable.

Conflicts of Interest: The authors declare no conflict of interest.

\section{References}

1. Lei, Y.; Hu, Z.; Cao, B.; Chen, X.; Song, H. Enhancements of thermal insulation and mechanical property of silica aerogel monoliths by mixing graphene oxide. Mater. Chem. Phys. 2017, 187, 183-190. [CrossRef]

2. Lee, K.-Y.; Mahadik, D.B.; Parale, V.G.; Park, H.-H. Composites of silica aerogels with organics: A review of synthesis and mechanical properties. J. Korean Ceram. Soc. 2020, 57, 1-23. [CrossRef]

3. Zhang, M.; Liu, Q.; Tian, S.; Zhou, X.; Liu, B.; Zhao, X.; Tang, G.; Pang, A. Facile synthesis of silica composite films with good mechanical property for spectrally broad band antireflection coatings. Colloids Surf. A 2021, 628, 127255. [CrossRef]

4. Kim, Y.J.; Yoo, S.H.; Lee, H.G.; Won, Y.; Cho, J.; Kang, K. Structural analysis of silica aerogels for the interlayer dielectric in semiconductor devices. Ceram. Int. 2021, 47, 29722-29729. [CrossRef]

5. Yorov, K.E.; Kolesnik, I.V.; Romanova, I.P.; Mamaeva, Y.B.; Sipyagina, N.A.; Lermontov, S.A.; Kopitsa, G.P.; Baranchikov, A.E.; Ivanov, V.K. Engineering $\mathrm{SiO}_{2}-\mathrm{TiO}_{2}$ binary aerogels for sun protection and cosmetic applications. J. Supercrit. Fluids 2021, 169, 105099. [CrossRef]

6. Caputo, G.; Marco, I.D.; Reverchon, E. Silica aerogel-metal composites produced by supercritical adsorption. J. Supercrit. Fluids 2010, 54, 243-249. [CrossRef] 
7. Matias, T.; Marques, J.; Quina, M.J.; Gando-Ferreira, L.; Valente, A.J.M.; Portugal, A.; Durães, L. Silica-based aerogels as adsorbents for phenol-derivative compounds. Colloids Surf. A 2015, 480, 260-269. [CrossRef]

8. Smirnova, I.; Suttiruengwong, S.; Arlt, W. Feasibility study of hydrophilic and hydrophobic silica aerogels as drug delivery systems. J. Non-Cryst. Solids 2004, 350, 54-60. [CrossRef]

9. Yamanaka, M.; Nakano, K.; Matsumura, Y.; Tanahashi, T. Perfluoropolyether Oil Diffusion Preventing Agent, and a Fluorine-Based Lubricant. JP6281084B2, 2 February 2018.

10. Mahadik, D.B.; Leea, Y.K.; Chavan, N.K.; Mahadik, S.A.; Park, H.-H. Monolithic and shrinkage-free hydrophobic silica aerogels via new rapid supercritical extraction process. J. Supercrit. Fluids 2016, 107, 84-91. [CrossRef]

11. Wei, T.-Y.; Chang, T.-F.; Lu, S.-Y.; Chang, Y.-C. Preparation of monolithic silica aerogel of low thermal conductivity by ambient pressure drying. J. Am. Ceram. Soc. 2007, 90, 2003-2007. [CrossRef]

12. Baetens, R.; Jelle, B.P.; Gustavsen, A. Aerogel insulation for building applications: A state-of-the-art review. Energy Build. 2011, 43, 761-769. [CrossRef]

13. Bhagat, S.D.; Kim, Y.-H.; Suh, K.-H.; Ahn, Y.-S.; Yeo, J.-G.; Han, J.-H. Superhydrophobic silica aerogel powders with simultaneous surface modification, solvent exchange and sodium ion removal from hydrogels. Microporous Mesoporous Mater. 2008, 112, 504-509. [CrossRef]

14. Huber, L.; Zhao, S.; Malfait, W.J.; Vares, S.; Koebel, M.M. Fast and minimal-solvent production of superinsulating silica aerogel granulate. Angew. Chem. Int. Ed. 2017, 56, 4753-4756. [CrossRef] [PubMed]

15. Lee, K.-J.; Kim, Y.H.; Lee, J.K.; Hwang, H. Fast synthesis of spherical silica aerogel powders by emulsion polymerization from water glass. ChemistrySelect 2018, 3, 1257-1261. [CrossRef]

16. Pan, Y.; He, S.; Cheng, X.; Li, Z.; Li, C.; Huang, Y.; Gong, L. A fast synthesis of silica aerogel powders-based on water glass via ambient drying. J. Sol-Gel Sci. Technol. 2017, 82, 594-601. [CrossRef]

17. Benslimane, A.; Bahlouli, I.M.; Bekkour, K.; Hammiche, D. Thermal gelation properties of carboxymethyl cellulose and bentonitecarboxymethyl cellulose dispersions: Rheological considerations. Appl. Clay Sci. 2016, 132, 702-710. [CrossRef]

18. Sarkar, N. Thermal gelation properties of methyl and hydroxypropyl methylcellulose. J. Appl. Polym. Sci. 1979, $24,1073-1087$. [CrossRef]

19. Ge, D.; Yang, L.; Li, Y.; Zhao, J. Hydrophobic and thermal insulation properties of silica aerogel/epoxy composite. J. Non-Cryst. Solids 2009, 355, 2610-2615. [CrossRef]

20. Piñero, M.; del Mar Mesa-Díaz, M.; de los Santos, D.; Reyes-Peces, M.V.; Díaz-Fraile, J.A.; de la Rosa-Fox, N.; Esquivias, L.; Morales-Florez, V. Reinforced silica-carbon nanotube monolithic aerogels synthesised by rapid controlled gelation. J. Sol-Gel. Sci. Tech. 2018, 86, 391-399. [CrossRef]

21. Wang, J.; Zhang, Y.; Wei, Y.; Zhang, X. Fast and one-pot synthesis of silica aerogels via a quasi-solvent-exchange-free ambient pressure drying process. Microporous Mesoporous Mater. 2015, 218, 192-198. [CrossRef]

22. Sarawade, P.B.; Kim, J.-K.; Hilonga, A.; Kim, H.T. Production of low-density sodium silicate-based hydrophobic silica aerogel beads by a novel fast gelation process and ambient pressure drying process. Solid State Sci. 2010, 12, 911-918. [CrossRef]

23. He, S.; Huang, D.; Bi, H.; Li, Z.; Yang, H.; Cheng, X. Synthesis and characterization of silica aerogels dried under ambient pressure bed on water glass. J. Non-Cryst. Solids 2015, 410, 58-64. [CrossRef]

24. Hamouda, A.A.; Amiri, H.A.A. Factors affecting alkaline sodium silicate gelation for in-depth reservoir profile modification. Energies 2014, 7, 568-590. [CrossRef]

25. Dorcheh, A.S.; Abbasi, M.H. Silica aerogel; synthesis, properties and characterization. J. Mater. Process. Tech. 2008, 199, 10-26. [CrossRef]

26. Iswar, S.; Malfait, W.J.; Balog, S.; Winnefeld, F.; Lattuada, M.; Koebel, M.M. Effect of aging on silica aerogel properties. Microporous Mesoporous Mater. 2017, 241, 293-302. [CrossRef]

27. Auniq, R.B.-Z.; Pakasri, N.; Boonyang, U. Synthesis and in vitro bioactivity of three-dimensionally ordered macroporousmesoporous bioactive glasses; 45S5 and S53P4. J. Korean Ceram. Soc. 2020, 57, 305-313. [CrossRef]

28. Pan, Y.; He, S.; Gong, L.; Cheng, X.; Li, C.; Li, Z.; Liu, Z.; Zhang, H. Low thermal-conductivity and high thermal stable silica aerogel based on MTMS/Water-glass co-precursor prepared by freeze drying. Mater. Des. 2017, 113, 246-253. [CrossRef]

29. Alison, L.; Demirörs, A.F.; Tervoort, E.; Teleki, A.; Vermant, J.; Studart, A.R. Emulsions stabilized by chitosan-modified silica nanoparticles: PH control of structure-Property relations. Langmuir 2018, 21, 6147-6160. [CrossRef]

30. Shewale, P.M.; Rao, A.V.; Rao, A.P. Effect of different trimethyl silylating agents on the hydrophobic and physical properties of silica aerogels. Appl. Surf. Sci. 2008, 254, 6902-6907. [CrossRef]

31. He, S.; Huang, Y.; Chen, G.; Feng, M.; Dai, H.; Yuan, B.; Chen, X. Effect of heat treatment on hydrophobic silica aerogel. J. Hazardou Mater. 2019, 362, 294-302. [CrossRef]

32. Feng, Q.; Chen, K.; Ma, D.; Lin, H.; Liu, Z.; Qin, S.; Luo, Y. Synthesis of high specific surface area silica aerogel from rice husk ash via ambient pressure drying. Colloids Surf. A 2018, 539, 399-406. [CrossRef]

33. Hwang, H. The development of high performance silica aerogel spheres. Unpublished work, 2019. 